ARTICLE

\title{
Dearomative 1,4-difunctionalization of naphthalenes via palladium-catalyzed tandem Heck/Suzuki coupling reaction
}

Bo Zhou ${ }^{1,5}$, Hongliang Wang ${ }^{2,5}$, Zhong-Yan Cao ${ }^{1}$, Jia-Wen Zhu', Ren-Xiao Liang ${ }^{1}$, Xin Hong ${ }^{2,3 凶}$ \& Yi-Xia Jia (iD) 1,4凶

Dearomative functionalization reactions represent an important strategy for the synthesis of valuable three-dimensional molecules from simple planar aromatics. Naphthalene is a challenging arene towards transition-metal-catalyzed dearomative difunctionalization reactions. Reported herein is an application of naphthalene as a masked conjugated diene in a palladium-catalyzed dearomative 1,4-diarylation or 1,4-vinylarylation reaction via tandem Heck/ Suzuki sequence. Three types of 1,4-dihydronaphthalene-based spirocyclic compounds are achieved in excellent regio- and diastereoselectivities. Key to this transformation is the inhibition of a few competitive side reactions, including intramolecular naphthalenyl $\mathrm{C}-\mathrm{H}$ arylation, intermolecular Suzuki cross-coupling, dearomative 1,2-difunctionalization, and dearomative reductive-Heck reaction. Density functional theory (DFT) calculations imply that the facile exergonic dearomative insertion of a naphthalene double bond disrupts the sequence of direct Suzuki coupling, leading to the tandem Heck/Suzuki coupling reaction. The observed regioselectivity towards 1,4-difunctionalization is due to the steric repulsions between the introduced aryl group and the spiro-scaffold in 1,2-difunctionalization.

\footnotetext{
${ }^{1}$ College of Chemical Engineering, State Key Laboratory Breeding Base of Green-Chemical Synthesis Technology, Zhejiang University of Technology, Hangzhou 310014, China. ${ }^{2}$ Department of Chemistry, Zhejiang University, Hangzhou 310058, China. ${ }^{3}$ State Key Laboratory of Clean Energy Utilization, Zhejiang University, Zheda Road 38, Hangzhou 310027, China. ${ }^{4}$ State Key Laboratory of Organometallic Chemistry, Shanghai Institute of Organic Chemistry, Chinese Academy of Sciences, Shanghai 200032, China. ${ }^{5}$ These authors contributed equally: Bo Zhou, Hongliang Wang. ${ }^{凶}$ email: hxchem@zju.edu.cn; yxjia@zjut.edu.cn
} 
O wing to the facile assembly of complex molecules starting from readily available olefins, transition-metal-catalyzed olefin difunctionalization has received considerable attention in past decades ${ }^{1-9}$. In this context, domino transformations involving initial carbometalation of simple alkenes or conjugated dienes and subsequent capture of the in situ generated $\sigma$-alkylmetal or $\pi$-allyl-metal species has been intensely developed for this purpose (Fig. 1a) ${ }^{10-16}$. On the other hand, as disclosed recently by the groups of Lautens ${ }^{17-20}$, Liang $^{21}$, Yin ${ }^{22,23}$, Zhou ${ }^{24}$, $\mathrm{Wu}^{25}$, and $\mathrm{us}^{26-30}$, the application of endocyclic $\mathrm{C}=\mathrm{C}$ bonds of heteroarenes as non-classic olefins has enabled a number of efficient dearomative difunctionalization reactions of indoles and furans with Pd- or Ni-catalyst ${ }^{31}$. This dearomatizing strategy undoubtedly expands the scope of olefin difunctionalization reaction to arenes and constitutes an important method for the synthesis of valuable three-dimensional molecules from simple planar aromatics ${ }^{32-38}$. However, the present study is still in its infancy and is limited to reactive heteroarenes, which tend to dearomatization due to their generally lower resonance stabilization energy. It is highly desirable to extend this reaction to additional aromatic compounds, in particular, for those less reactive arenes.

Naphthalene and benzene are abundant aromatic molecules while remain much less reactive toward the above-mentioned dearomative difunctionalization reactions $s^{34-39}$. When viewing naphthalene as a masked conjugated diene, not only dearomatizing carbometalation but also regioselective and diastereoselective capture of the in situ formed $\pi$-allyl-metal species remain challenging (Fig. 1b). In addition, competitive side reactions including naphthalenyl $\mathrm{C}-\mathrm{H}$ functionalization and the direct crosscoupling with capturing agents impeded this study. To our knowledge, there has no example reported for the dearomative difunctionalization of naphthalenes through palladium-catalyzed Heck/anionic-capture sequence ${ }^{40-50}$. As our interest of dearomatization reactions ${ }^{26-30,51-54}$, we report herein a dearomative 1,4-difunctionalization of naphthalenes via intramolecular dearomative Heck arylation or vinylation followed by intermolecular cross-coupling with the $\pi$-allyl-palladium species (Fig. 1c). A range of 1,4-dihydronaphthalene-based spirocycles bearing oxindole, dihydrobenzofuran, or indene subunits are achieved in moderate to excellent yields, which are frequently occurring structural frameworks in natural products and bioactive molecules. Both regioselectivity and remote diastereoselectivity of two newly formed carbocenters at $\mathrm{C} 1$ and $\mathrm{C} 4$ are well controlled. Key to this reaction relies on the inhibition of a few competitive side reactions, including intramolecular naphthalenyl C-H arylation, intermolecular Suzuki cross-coupling, 1,2-difunctionalization, and dearomative reductiveHeck reaction. DFT calculations reveal the mechanistic basis for the tandem Heck/Suzuki coupling reaction and the controlling factors of chemo- and regioselectivities.

\section{Results}

Optimization study. Our study began with the reaction optimization of $N$-(2-bromophenyl)- $N$-methyl-1-naphthamide 1a with phenylboronic acid $\mathbf{2 a}$ (Table 1). It has turned out that 1,4-product 3a was difficult to be achieved as a series of by-products 4-7 were observed in the reaction. As shown in Fig. 2, initial test in

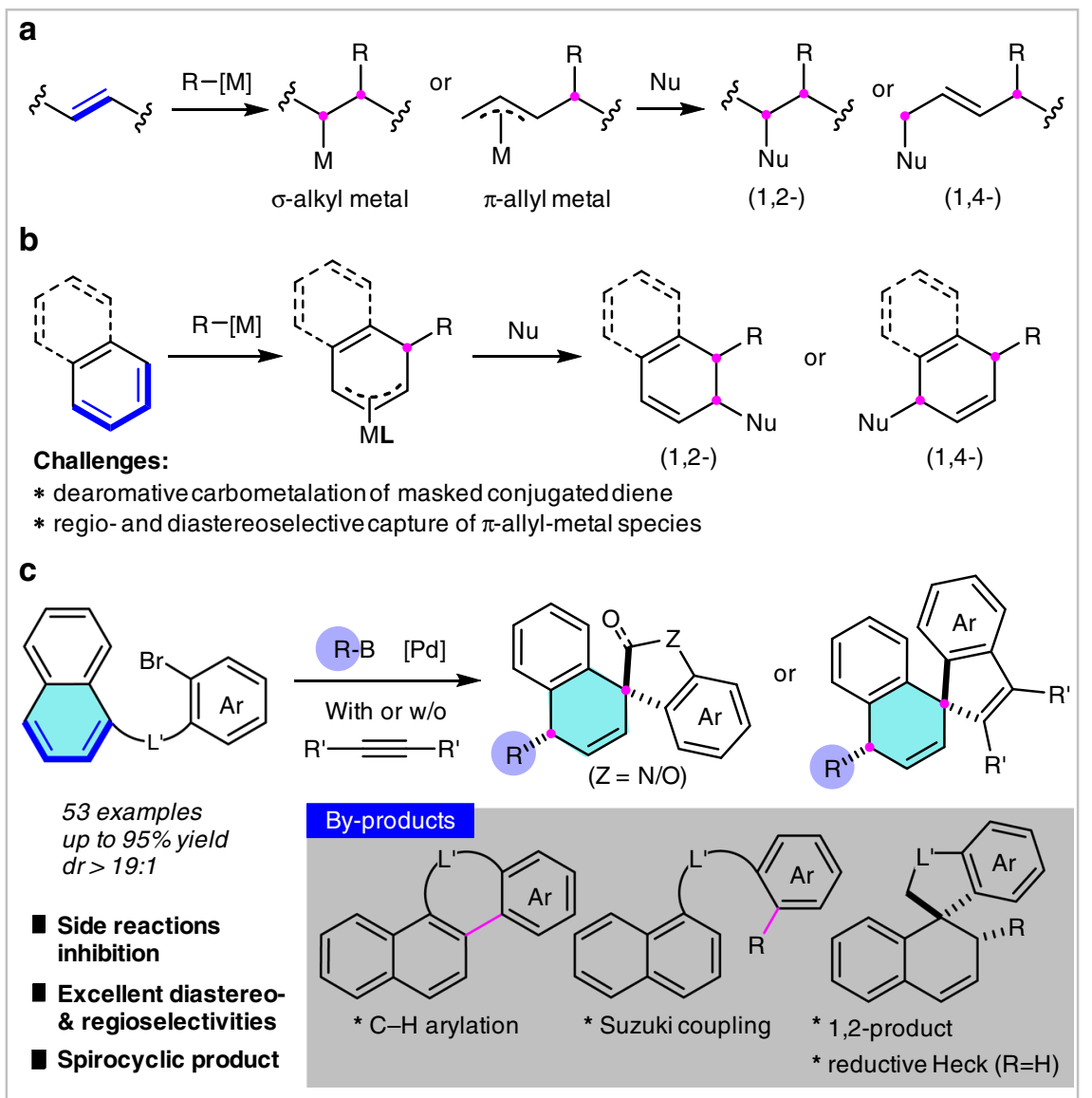

Fig. 1 Transition-metal-catalyzed difunctionalization of olefin and arene. a TM-catalyzed difunctionalization of alkene (well-developed) 2,9-16. b Dearomative difunctionalization of naphthalene or benzene (unknown). c Dearomative 1,4-diarylation/vinylarylation of naphthalenes via Heck/Suzuki coupling (This work). [M] metal catalyst, Nu nucleophile, L ligand, L' linker, Ar arene. 


\section{Table 1 Reaction optimizationa.}<smiles>[X]c1ccccc1N(C)C(=O)c1cccc2ccccc12</smiles><smiles></smiles>

3a $(d r>19: 1)$<smiles>CN1C(=O)[C@]2(c3ccccc3C=C[C@H]2P)c2ccccc21</smiles>

5: $R^{\prime}=H ; 6: R^{\prime}=P h$

$\begin{array}{ll}1 \mathrm{a} & \mathrm{X}=\mathrm{Br} \\ 1 \mathrm{a}^{\prime} & \mathrm{X}=1\end{array}$

$1 a^{\prime \prime} \quad X=C l$

$\mathrm{Pd}(\mathrm{dba})_{2}(5 \mathrm{~mol} \%)$

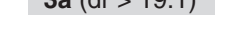<smiles>Cn1c(=O)c2c3ccccc3ccc2c2ccccc21</smiles>

$\mathrm{PhB}(\mathrm{OH})_{2} 2 \mathrm{a}$<smiles>CN(C(=O)c1cccc2ccccc12)c1ccccc1-c1ccccc1</smiles><smiles>COc1ccc2ccccc2c1-c1c(OP(N)N)ccc2ccccc12</smiles>

L1: $\mathrm{R}=\mathrm{Me}$

L2: $\mathrm{R}_{2}=-\left(\mathrm{CH}_{2}\right)_{4}$ -

L3: $\mathrm{R}=i-\mathrm{Pr}$

L4: $\mathrm{R}=\mathrm{Cy}$<smiles>c1cc2c3c(c1)OP(N(C1CCCCC1)C1CCCCC1)Oc1cccc(c1C31CCCC1)CC2</smiles>

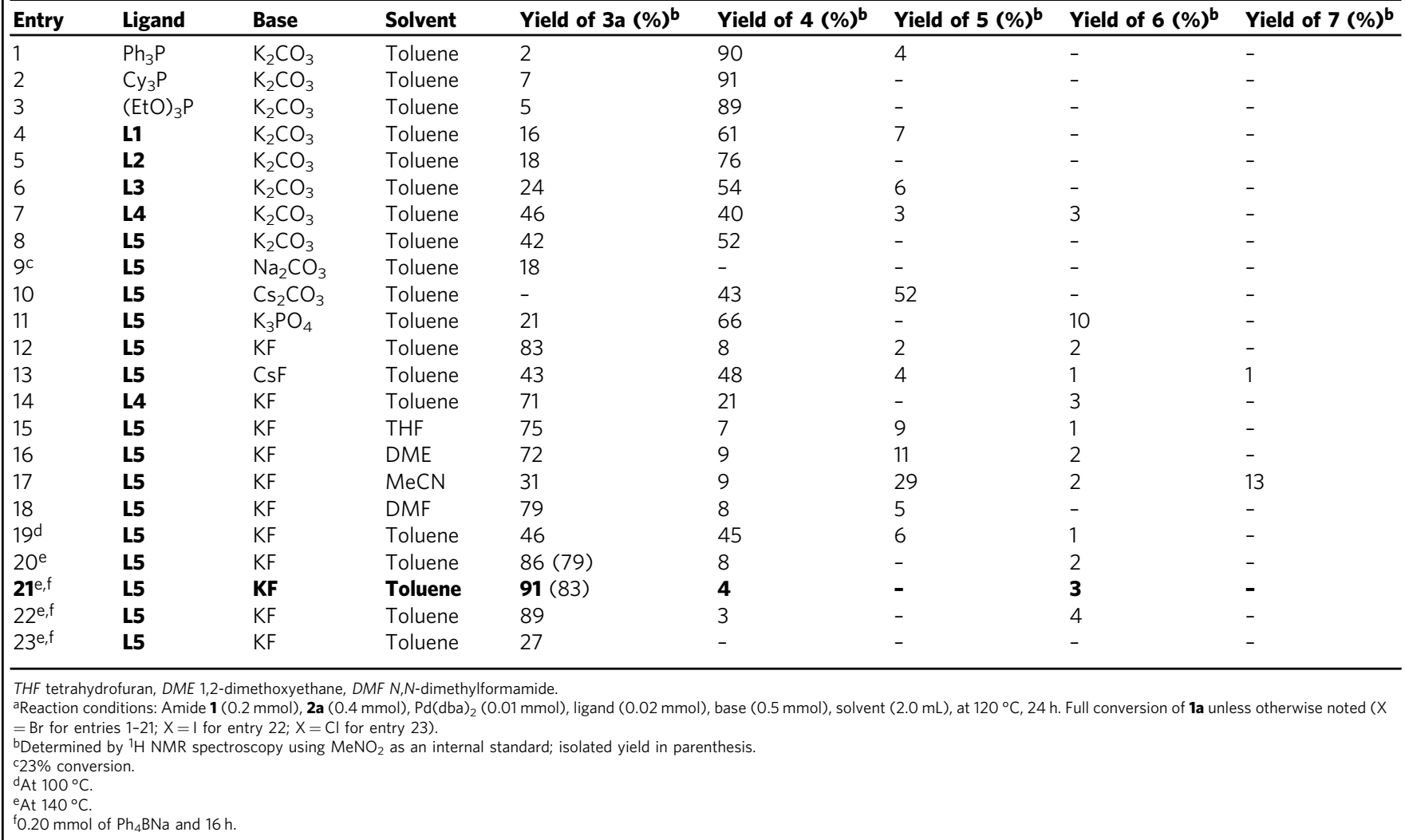

the presence of $5 \mathrm{~mol} \% \mathrm{Pd}(\mathrm{dba})_{2}, 10 \mathrm{~mol} \% \mathrm{PPh}_{3}$, and 2.5 equiv $\mathrm{K}_{2} \mathrm{CO}_{3}$ in toluene led to by-product 4 in $90 \%$ NMR (Nuclear Magnetic Resonance) yield via an intermolecular Suzuki crosscoupling (see also entry 1). Not surprisingly, the intramolecular naphthalenyl $\mathrm{C}-\mathrm{H}$ arylation reaction proceeded smoothly to afford compound 7 in $70 \%$ yield in the absence of phenylboronic acid 2a. Although the desired product 3a and by-product 5 were detected in very poor yields, it indicated the occurrence of naphthalene dearomatization.
Further ligand evaluation showed that the racemic BINOL ([1,1'-binaphthalene $]-2,2^{\prime}$-diol)-derived phosphoramidite L1 provided $3 \mathrm{a}$ in a promising yield (16\%) along with by-product 5 (7\%) derived from dearomative reductive-Heck reaction. $\mathrm{Cy}_{3} \mathrm{P}$ and (EtO) ${ }_{3} \mathrm{P}$ gave similar results as $\mathrm{PPh}_{3}$ (entries 2-4). Nevertheless, excellent diastereoselectivity (>19:1) was observed for 3a, whose structure and the relative configuration were determined by X-ray analysis. Encouraged by this result, other racemic phosphoramidites $\mathbf{L 2}-\mathbf{L} \mathbf{4}$ bearing different substituents on nitrogen atom were 


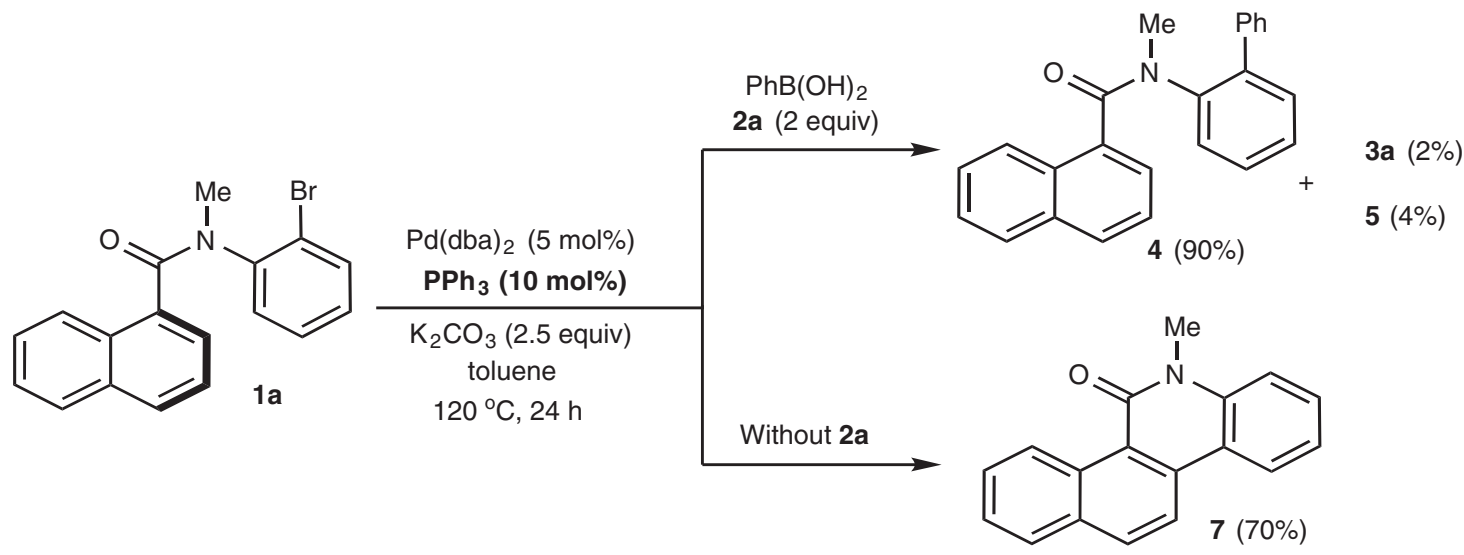

Fig. 2 Initial test with $\mathbf{P h}_{\mathbf{3}} \mathbf{P}$ as ligand. The yields refer to $\mathrm{NMR}$ yield using $\mathrm{MeNO}_{2}$ as an internal standard. dba (1E,4E)-1,5-diphenylpenta-1,4-dien-3-one.

examined subsequently (entries 5-7). It was found that steric hindrance of the amino moiety facilitated the formation of 3a. For example, $\mathbf{L} 4$ bearing a dicyclohexylamino group led to $3 \mathbf{a}$ in $46 \%$ yield along with the detection of by-products 4-6 (entry 7). Comparable yield of $\mathbf{3 a}$ was achieved for $\mathbf{L} \mathbf{5}$ containing a spirobackbone ${ }^{55}$, while compound $\mathbf{4}$ was the only by-product in this case (entry 8).

To further improve the product yield, influence of the base and solvent were then investigated in the presence of ligand L5 (entries 9-13 and 15-18). Gratifyingly, NMR yield of 3a was substantially improved to $83 \%$ by employing KF as a base (entry 12 ), whereas no product or lower yields were observed for $\mathrm{Na}_{2} \mathrm{CO}_{3}, \mathrm{Cs}_{2} \mathrm{CO}_{3}, \mathrm{~K}_{3} \mathrm{PO}_{4}$, and $\mathrm{CsF}$ (entries 9-11 and 13). As a comparison, the reaction using $\mathbf{L 4}$ as a ligand in the presence of KF base led to $\mathbf{3 a}$ in $71 \%$ yield (entry 14 ). Toluene was proved to be the best choice of solvent, although comparable yields were observed in THF, DME, and DMF (entries 15, 16, and 18). Noticeably, the reaction in MeCN led to relatively higher yields for by-products 5 and 7 (entry 17). Elevating the reaction temperature to $140{ }^{\circ} \mathrm{C}$ resulted in a slightly improved NMR yield of $\mathbf{3 a}(86 \%)$, which was isolated in $79 \%$ yield (entry 20$)$. Switching $\mathrm{PhB}(\mathrm{OH})_{2}$ to $\mathrm{Ph}_{4} \mathrm{BNa}$ further improved the isolated yield to $83 \%$, along with trace amount of by-product 4 and 1,2-isomer 6 (entry 21 ). It is noting that lower enantioselectivities of the product were observed when the corresponding chiral ligands were used (entry $4(S)$-L1, 16\% ee; entry $5(R)$-L2, 8\% ee; entry $6(S)$-L3, 12\% ee; entry $7(S)-\mathbf{L} 4,11 \%$ ee; entry $20(R)-\mathbf{L 5}, 5 \%$ ee). As shown in entries 22 and 23, the influence of halides in the substrate 1 was investigated. Product 3a was obtained in $89 \%$ NMR yield for iodo-substrate and $27 \%$ for the chloro-substrate.

Substrate scope evaluation. With the optimal conditions in hand, the scope of amide 1 was then evaluated (Fig. 3). Good yields and excellent diastereoselectivity (>19:1) were detected for the substrates bearing an aniline ring with different steric and electronic profiles. A variety of substituents, including $\mathrm{Me}, \mathrm{MeO}$, $\mathrm{CF}_{3}, \mathrm{~F}, \mathrm{Cl}, \mathrm{CF}_{3} \mathrm{O}$, acetyl, ester, and amide were well tolerated in the reaction. No steric effect was observed in the reactions of substrates bearing substituents ortho to bromide atom and the corresponding products $\mathbf{3 b} \mathbf{b} \mathbf{3} \mathbf{e}$ were achieved in good to excellent yields. In addition to $N$-methyl substrates, the reaction of $N$ benzyl substrate delivered product $3 \mathbf{u}$ in a higher yield (95\%). The reaction was also compatible with a pyridine-derived substrate, which afforded product $3 \mathbf{v}$ in $72 \%$ yield. Moreover, for the reaction of substrate bearing an extra bromide atom on the naphthalene ring, an unsurprisingly diphenylated product $\mathbf{3} \mathbf{x}$ was isolated in $71 \%$ yield with excess amount of $\mathrm{Ph}_{4} \mathrm{BNa}$ and $\mathrm{KF}$. Excellent yield was also observed for product $3 \mathbf{w}$ containing a methoxy group on naphthalene ring. Interestingly, although $\mathrm{Cl}$ atom at $\mathrm{C} 5$ of product $\mathbf{3 j}$ survived in the reaction, $\mathrm{Cl}$ para to bromide coupled with $\mathrm{Ph}_{4} \mathrm{BNa}$ to afford diphenylated product $3 \mathrm{y}$ in $58 \%$ yield. In these two cases three $\mathrm{C}-\mathrm{C} \sigma$-bonds were generated in one step. Extension of the reaction to 1,4-difunctionalization of benzene was unsuccessful, while excellent yield of $88 \%$ was achieved for an antracene-substrate $1 z$. When a para-MeOsubstrate 8 was used, the 1,4-diarylation product 9 was isolated in $51 \%$ yield as a major product along with 1,2-product $\mathbf{1 0}$ in $22 \%$ yield.

Considering the commercial availability of aromatic boronic acids, we then applied them as coupling partners for this 1,4difunctionalization reaction. As shown in Table 2, reactions of $\mathbf{1 a}$ with various of boronic acids 2 bearing different substituents, such as $\mathrm{Me}, \mathrm{F}, \mathrm{Cl}, \mathrm{CF}_{3}$, and $\mathrm{Ph}$, at $o-/ m$ - $/ \mathrm{p}$-positions of benzene ring proceeded well to afford the desired products in $50-90 \%$ yields with excellent diastereoselectivity (>19:1). Noteworthy is that a vinyl moiety bearing on the benzene ring of 2 has no disturbance to the reaction, affording product 3 ai in $46 \%$ yield (entry 9). Other than 1-naphthamide substrate, the reaction is also compatible with arylether tethered naphthalene 11. Under the standard conditions, the anticipated 1,4-diarylation product 12 was afforded in 55\% yield and with >19:1 diastereomeric ratio (Fig. 4). This not only extends the scope of naphthalene, but also provides a reliable synthetic approach to dihydrobenzofuranderived spirocycle.

Theoretical calculation study. To shed light on the reaction mechanism and origins of chemo- and regioselectivities, density functional theory (DFT) calculations were performed using the $N$-(2-bromophenyl)- $N$-methyl-1-naphthamide $\mathbf{1 a}$ and phenylboronic acid $\mathbf{2 a}$ as the model. The computed free energy changes of the tandem Heck/Suzuki reaction (black pathway) and the intermolecular Suzuki cross-coupling reaction (blue pathway) are shown in Fig. 5. From the $\operatorname{Pd} \mathbf{L}_{2}$ complex, ligand exchange with 1a leads to the arene-coordinated intermediate int1. Subsequent oxidative addition via TS2 generates the $\mathrm{Pd}(\mathrm{II})$ intermediate int3, which undergoes insertion through TS4 to form the allyl-palladium intermediate int5. Transmetalation of int5 with $\mathrm{PhB}(\mathrm{OH})_{2} \mathrm{~F}$ anion (see Supplementary Fig. 185 for the formation of $\mathrm{PhB}(\mathrm{OH})_{2} \mathrm{~F}$ anion) via TS7 irreversibly affords the (allyl)palladium(phenyl) intermediate int8. Subsequent reductive elimination through TS9 eventually produces the Heck/Suzuki product $3 \mathbf{a}$ and regenerates the $\operatorname{Pd}(0)$ active catalyst. Alternatively, int3 can also directly undergoes transmetalation with $\mathrm{PhB}(\mathrm{OH})_{2} \mathrm{~F}$ anion to form the biarylpalladium(II) intermediate int12. Subsequent aryl-aryl reductive elimination through TS13 would produce the classic intermolecular Suzuki cross-coupling 
<smiles>CCN(C(=O)c1cccc2ccccc12)c1ccccc1Br</smiles>
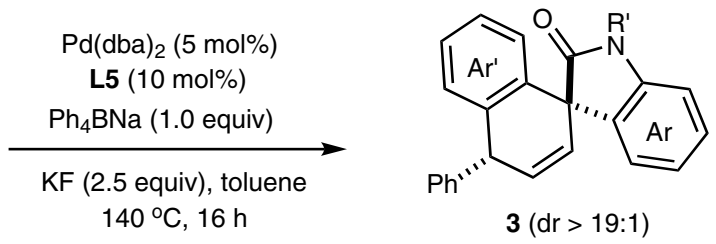<smiles>C[R]1C=Cc2ccccc2[C@]12C=C[C@H](c1ccccc1)c1ccccc12</smiles>

3f: $\mathrm{R}=5-\mathrm{Me}, 91 \%$

3g: $\mathrm{R}=5-\mathrm{OMe}, 77 \%$

3h: $\mathrm{R}=5-\mathrm{OCF}_{3}, 77 \%$

3i: $R=5-F, 79 \%$

3j: $\mathrm{R}=5-\mathrm{Cl}, 69 \%$

3k: $\mathrm{R}=5-\mathrm{CF}_{3}, 87 \%$

3l: $R=5-A c, 64 \%$ 3a: $\mathrm{R}=\mathrm{H}, 83 \%$

3b: $R=4-M e, 83 \%$

3c: $R=4-\mathrm{OMe}, 90 \%$

3d: $R=4-F, 87 \%$

3e: $R=4-\mathrm{CF}_{3}, 83 \%$

$3 \mathrm{~m}: \mathrm{R}=6-\mathrm{Me}, 83 \%$

3n: $R=6-\mathrm{OMe}, 81 \%$

3o: $\mathrm{R}=6-\mathrm{OCF}_{3}, 92 \%$

3p: $R=6-F, 90 \%$

3q: $\mathrm{R}=6-\mathrm{CF}_{3}, 84 \%$

3r: $\mathrm{R}=6-\mathrm{CO}_{2} \mathrm{Me}, 80 \%$

3s: $\mathrm{R}=6-\mathrm{CONEt}_{2}, 90 \%$

3t: $R=5,6-F_{2}, 78 \%$<smiles>[X]c1cccc2c1N([R])C(=O)[C@]21C=C[C@H](c2ccccc2)c2ccccc21</smiles>

3u: $\mathrm{R}=\mathrm{Bn}, \mathrm{X}=\mathrm{CH}, 95 \%$ 3v: $R=M e, X=N, 72 \%$

$\mathrm{MeO}$<smiles>CN1C(=O)[C@@]2(C=C[C@H](c3ccccc3)c3ccccc32)c2ccccc21</smiles>

3w: $91 \%$<smiles>CN(C(=O)c1cccc2c(Br)cccc12)c1ccccc1Br</smiles>

Three $C-C \sigma$-bonds formation<smiles>CN(C(=O)c1cccc2ccccc12)c1cc(Cl)ccc1Br</smiles>

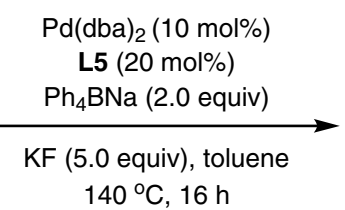

$140^{\circ} \mathrm{C}, 16 \mathrm{~h}$

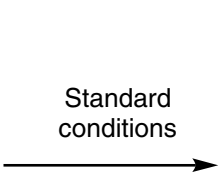<smiles>CN(C(=O)c1cccc2cc3ccccc3cc12)c1ccccc1Br</smiles>

$1 z$<smiles>CN1C(=O)[C@]2(C=C[C@H](c3ccccc3)c3c(-c4ccccc4)cccc32)c2ccccc21</smiles>

3x: $71 \%$<smiles>CN1C(=O)[C@@]2(C=C[C@H](c3ccccc3)c3ccccc32)c2ccc(-c3ccccc3)cc21</smiles>

3y: $58 \%$<smiles>CN1C(=O)[C@]2(C=C[C@H](c3ccccc3)c3cc4ccccc4cc32)c2ccccc21</smiles><smiles>COc1ccc(C(=O)N(C)c2ccccc2Br)c2ccccc12</smiles><smiles>CO[C@]1(c2ccccc2)C=C[C@]2(C(=O)Nc3ccccc32)c2ccccc21</smiles><smiles>COC1=C[C@H](c2ccccc2)[C@@]2(C(=O)Nc3ccccc32)c2ccccc21</smiles>

Fig. 3 Substrate scope of amides. The standard reaction conditions were used, as shown in Table 1, entry 21. Isolated yield are presented.

product 4. The overall barrier for the formation of Heck/Suzuki product $3 \mathrm{a}$ is $1.5 \mathrm{kcal} / \mathrm{mol}$ lower than that for the formation of 4 (TS7 vs TS11), indicating that the formation of $\mathbf{3 a}$ is more favorable than that of 4 . This is consistent with the experimental results that the ratio of $\mathbf{3 a}$ and $\mathbf{4}$ is $86: 8$ (Table 1 , entry 20). Therefore, the chemoselectivity-determining transmetalation step differentiates the tandem Heck/Suzuki coupling reaction and the competing classic intermolecular Suzuki cross-coupling. The 
Table 2 Scope of boronic acidsa.<smiles>O=C(c1cccc2ccccc12)N(c1ccccc1Br)[N+](=O)[O-]</smiles>
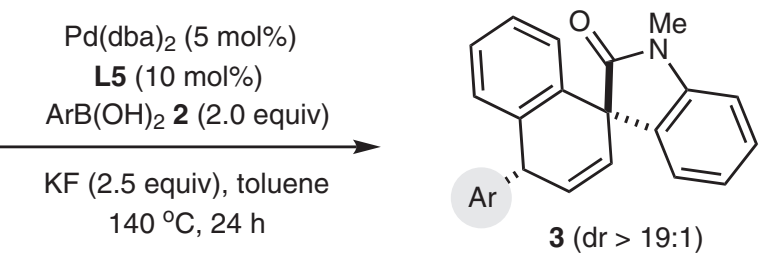

\begin{tabular}{llll}
\hline Entry & Ar & 3 & Yield (\%) \\
\hline 1 & $2-\mathrm{MeC}_{6} \mathrm{H}_{4}$ & $\mathbf{3 a a}$ & 81 \\
2 & $3-\mathrm{MeC}_{6} \mathrm{H}_{4}$ & $\mathbf{3 a b}$ & 75 \\
3 & $3-\mathrm{FC}_{6} \mathrm{H}_{4}$ & $\mathbf{3 a c}$ & 77 \\
4 & $3-\mathrm{ClC}_{6} \mathrm{H}_{4}$ & $\mathbf{3 a d}$ & 61 \\
5 & $4-\mathrm{FC}_{6} \mathrm{H}_{4}$ & $\mathbf{3 a e}$ & 78 \\
$6^{b}$ & $4-\mathrm{ClC}_{6} \mathrm{H}_{4}$ & $\mathbf{3 a f}$ & 50 \\
$7^{b}$ & $4-\mathrm{CF}_{3} \mathrm{C}_{6} \mathrm{H}_{4}$ & $\mathbf{3 a g}$ & 55 \\
$8^{b}$ & $4-\mathrm{PhC}_{6} \mathrm{H}_{4}$ & $\mathbf{3 a h}$ & 50 \\
9 & $4-\mathrm{vinylC}_{6} \mathrm{H}_{4}$ & $\mathbf{3 a i}$ & 46 \\
10 & $3,4-\mathrm{F}_{2} \mathrm{C}_{6} \mathrm{H}_{3}$ & $\mathbf{3 a j}$ & \\
11 & $3-\mathrm{Cl}_{4}-\mathrm{FC}_{6} \mathrm{H}_{3}$ & $\mathbf{3 a k}$ & 60 \\
\end{tabular}

aThe standard reaction conditions were used, as shown in Table 1, entry 21 (using arylboronic acid instead of $\mathrm{Ar}_{4} \mathrm{BNa}$ ). Isolated yield is presented. Reaction time was $36 \mathrm{~h}$<smiles>COC(=O)c1ccc(Br)c(OCc2cccc3ccccc23)c1</smiles>
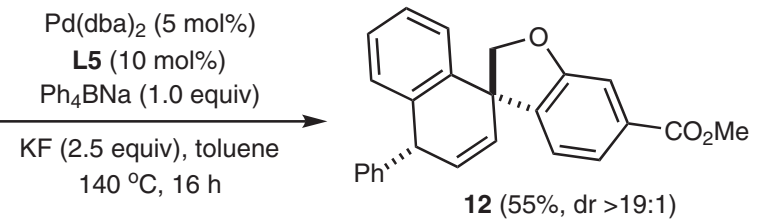

Fig. 4 1,4-Diarylation of arylether tethered naphthalene 11. Reaction conditions: $11(0.2 \mathrm{mmol}), \mathrm{Pd}(\mathrm{dba})_{2}(0.01 \mathrm{mmol}), \mathbf{L 5}(0.02 \mathrm{mmol}), \mathrm{Ph}{ }_{4} \mathrm{BNa}(0.2$ $\mathrm{mmol}), \mathrm{KF}(0.5 \mathrm{mmol})$, toluene $(2 \mathrm{~mL}), 140{ }^{\circ} \mathrm{C}, 16 \mathrm{~h}$, isolated yield.

facile exergonic insertion of pendant naphthalene double bond via TS4 interrupts the sequence of Suzuki cross-coupling and drives the reaction toward the tandem Heck/Suzuki coupling reaction. We have also considered a number of alternative mechanistic pathways, and the details of these unfavorable pathways are included in the Supporting Information (Supplementary Figs. 187 and 188).

Based on the mechanistic model, we next explored the regioselectivity of 1,4- and 1,2-diarylation. The energies and optimized structures of the competing reductive elimination transition states are shown in Fig. 6 (see Supplementary Fig. 188 for the entire DFT-computed Gibbs free energy profile of the regioisomeric 1,2-difunctionalization). TS9 is $3.0 \mathrm{kcal} / \mathrm{mol}$ more favorable than TS14, which is consistent with the experimental observations of 1,4-diarylation as the major product. The 1,2-diarylation is less favorable due to the steric repulsions between the phenyl moiety of the forming $\mathrm{C}-\mathrm{C}$ bond and the spiro-scaffold. Indeed, replacing the spiroscaffold with methylene led to a reversed chemoselectivity (see Supplementary Fig. 189). This suggested that the intrinsic chemoselectivity favors the 1,2-difunctionalization because of the conjugation in the styrene product, while the steric repulsions overrule the intrinsic preference and favors the 1,4-difunctionalization.
Three-component dearomative reaction. We further envisioned a three-component tandem reaction between 1-(2-bromophenyl) naphthalene 13, alkyne 14, and sodium tetraarylborates to synthesize indene-derived spirocarbocycles. In this dearomative 1,4vinylarylation reaction, three $\mathrm{C}-\mathrm{C}$ bonds would generate in one step through the first insertion of Ar-Pd species to alkyne, the second insertion of the resulting alkenyl-Pd intermediate to naphthalene, and the final transmetalation with tetraphenylborate followed by reductive elimination. To our delight, under the above optimal conditions, both aryl and alkyl substituted internal alkynes reacted smoothly with naphthalene 13 and $\mathrm{Ph}_{4} \mathrm{BNa}$, offering the spirocarbocycles $\mathbf{1 5 a}-\mathbf{1 5} \mathbf{i}$ in moderate to good yields with excellent diastereoselectivities (Table 3, entries 1-9). Effect of the substituents attached on the benzene ring of arylbromides was also tested, which afforded the desired products $\mathbf{1 5} \mathbf{j}-\mathbf{1 5 n}$ in the yields ranging from $55 \%$ to $83 \%$ (entries 10-13).

Scale-up reaction and product transformation. To demonstrate the practicality of this protocol, a scale-up reaction was carried out and product 3a was isolated in $87 \%$ yield (Fig. 7 a). As shown in Fig. 7b, non-conjugated carbon-carbon double bond of $\mathbf{3 a}$ was prone to isomerization in the presence of ${ }^{t} \mathrm{BuOK}$, affording spirooxindole 16 bearing a styrene moiety in $91 \%$ yield. 


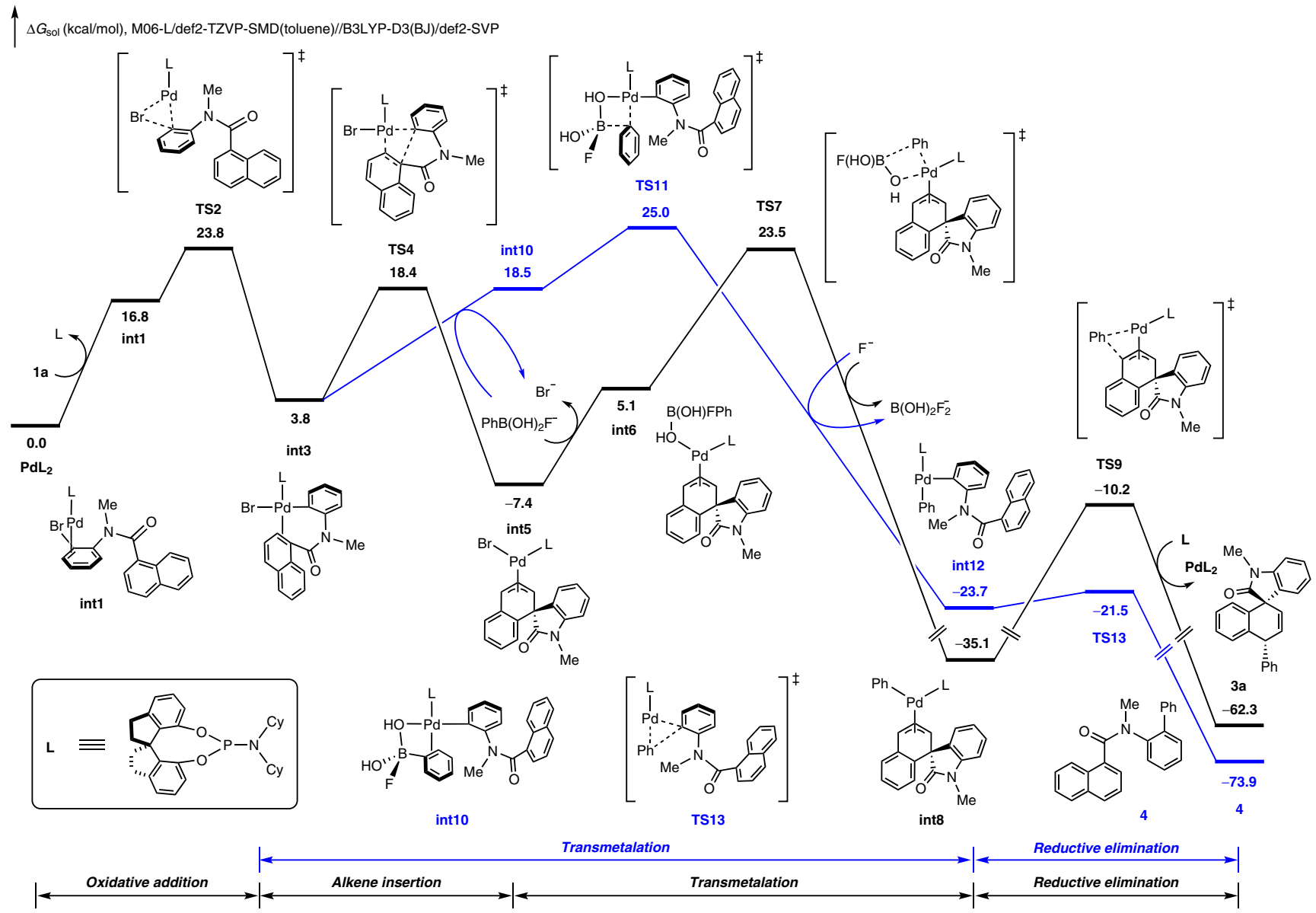

Fig. 5 Theoretical calculations. DFT-computed free energy profiles of the most favorable pathway for the formation of $\mathbf{3 a}$ and by-product $\mathbf{4}$ ( $\mathbf{L}=\mathbf{L 5}$ ).
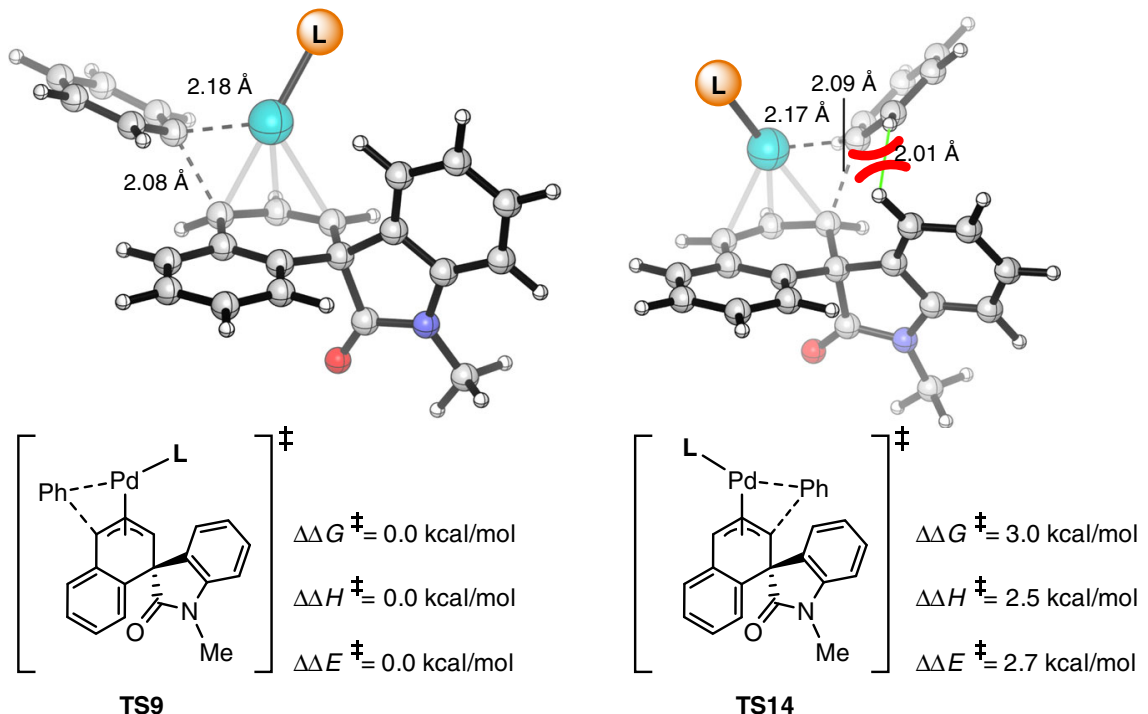

Fig. 6 Theoretical calculations. DFT-computed free energies of the regioselectivity-determining reductive elimination transition states $(\mathbf{L}=\mathbf{L 5})$.

Moreover, a Pd/C-catalyzed hydrogenation of alkene with $\mathrm{H}_{2}$ balloon led to saturated spirocarbocycle $\mathbf{1 7}$ in $92 \%$ yield. It is noted that compounds $\mathbf{3 a}, \mathbf{1 6}$, and $\mathbf{1 7}$ are analogs of a patented bioactive molecule for treating pain ${ }^{56}$, which indicates further potential application of the present method.
In summary, an efficient dearomative 1,4-diarylation of naphthalenes has been developed through palladium-catalyzed tandem Heck/Suzuki coupling reaction. A few competitive side reactions are overcome with excellent control of chemo-, regio-, and diastereoselectivities in this reaction. This protocol is further 
Table 3 Three-component dearomative 1,4-vinylarylation reactiona.

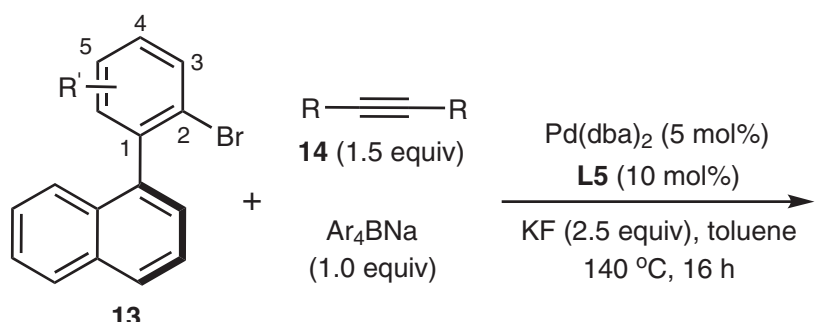<smiles>[R]C1=C([R])[C@]2(C=C[C@@H](Br)c3ccccc32)c2ccccc21</smiles>

$15(\mathrm{dr}>19: 1)$

\begin{tabular}{|c|c|c|c|c|c|}
\hline Entry & $\mathbf{R}^{\prime}$ & $\mathbf{R}$ & Ar & 15 & Yield (\%) \\
\hline
\end{tabular}

a<smiles>CN(C(=O)c1cccc2ccccc12)c1ccccc1Br</smiles><smiles>CN1C(=O)[C@]2(C=C[C@H](c3ccccc3)c3ccccc32)c2ccccc21</smiles>

$1 \mathrm{a}(1.0 \mathrm{mmol})$

3a $(87 \%, d r>19: 1)$

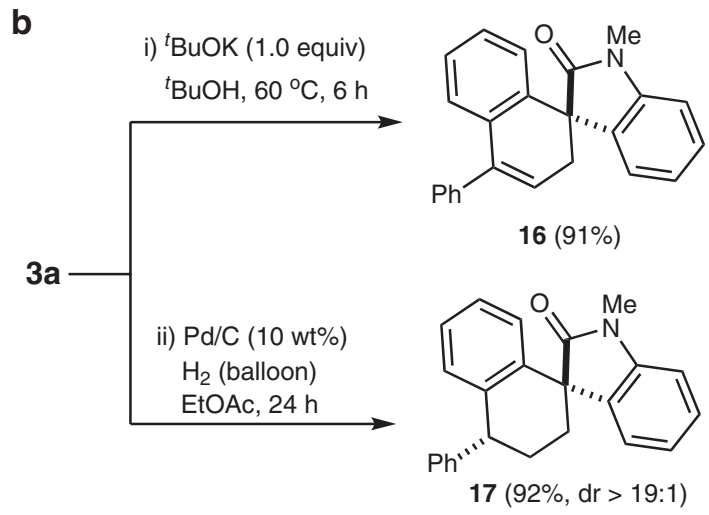

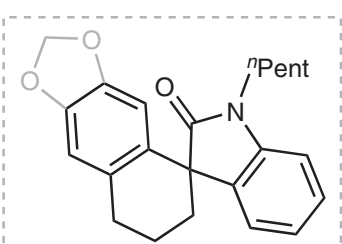

For treating pain

Fig. 7 Scale-up reaction and synthetic transformations. a $1.0 \mathrm{mmol}$ scale-synthesis of product $\mathbf{3 a}$. $\mathbf{b}$ Transformations of product $\mathbf{3 a}$. (i) isomerization of carbon-carbon double bond of $\mathbf{3 a}$ with ${ }^{\mathrm{B}} \mathrm{BuOK}$. (ii) reduction of carbon-carbon double bond of $\mathbf{3 a}$ with $\mathrm{Pd} / \mathrm{C}$ catalyst under $\mathrm{H}_{2}$ atmosphere.

extended to three-component dearomative 1,4-vinylarylation of naphthalenes with alkynes and tetraarylborates. The dearomative 1,4-difunctionalization reaction has provided facile accesses to unique spirocyclic compounds. DFT calculations revealed the reaction mechanism and elucidated the origins of chemo- and regioselectivities. It is the facile exergonic insertion of naphthalene double bond that disrupts the sequence of direct Suzuki coupling, leading to the tandem Heck/Suzuki coupling reaction. The steric repulsions between the aryl group of the forming $\mathrm{C}-\mathrm{C}$ bond and the spiro-scaffold disfavors the intrinsic regioselectivity toward 1,2-difunctionalization, allowing the observed 1,4difunctionalization.

\section{Methods}

General procedure for the reaction of $\mathbf{1 , 8}$, or 11. To a dried Schlenk tube were added 1, 8, or $11(0.20 \mathrm{mmol}), \mathrm{Pd}(\mathrm{dba})_{2}(5.8 \mathrm{mg}, 0.010 \mathrm{mmol})$, ligand $\mathbf{L} 5(9.2 \mathrm{mg}$, $0.020 \mathrm{mmol}), \mathrm{NaBPh}_{4}(68.4 \mathrm{mg}, 0.20 \mathrm{mmol})$ or $\mathrm{ArB}(\mathrm{OH})_{2}(0.40 \mathrm{mmol})$, KF $(29.1$ $\mathrm{mg}, 0.50 \mathrm{mmol}$ ) under $\mathrm{N}_{2} .2 .0 \mathrm{~mL}$ toluene was then introduced via syringe and the 
tube was sealed using Teflon cap. The mixture was stirred at $140{ }^{\circ} \mathrm{C}$ until the starting material was consumed. The solvent was then removed under vacuum and the residue was purified by chromatography on silica gel, eluting with ethyl acetate/ petroleum ether to afford the products 3,9 , or 12 .

General procedure for the reaction of 13. To a dried Schlenk tube were added $\mathbf{1 3}$ $(0.20 \mathrm{mmol})$ and $14(0.30 \mathrm{mmol}), \mathrm{Pd}(\mathrm{dba})_{2}(5.8 \mathrm{mg}, 0.010 \mathrm{mmol})$, ligand $\mathbf{L 5}(9.2$ $\mathrm{mg}, 0.02 \mathrm{mmol}), \mathrm{Ar}_{4} \mathrm{BNa}(0.20 \mathrm{mmol}), \mathrm{KF}(29.1 \mathrm{mg}, 0.50 \mathrm{mmol})$ under $\mathrm{N}_{2} .2 .0 \mathrm{~mL}$ toluene was then introduced via syringe and the tube was sealed using Teflon cap. The mixture was stirred at $140^{\circ} \mathrm{C}$ for $16 \mathrm{~h}$. The solvent was then removed under vacuum and the residue was purified by chromatography on silica gel, eluting with dichloromethane/petroleum ether to afford the products 15.

\section{Data availability}

The X-ray crystallographic coordinate for structure reported in this study have been deposited at the Cambridge Crystallographic Data Centre (CCDC) under deposition numbers CCDC-1969160 (3a). These data can be obtained free of charge from The Cambridge Crystallographic Data Centre via www.ccdc.cam.ac.uk/data_request/cif. The authors declare that all other data supporting the findings of this study are available within the article and Supplementary information files, and also are available from the corresponding author upon reasonable request.

Received: 2 April 2020; Accepted: 4 August 2020;

Published online: 01 September 2020

\section{References}

1. Muñiz, K. Imido-osmium (VIII) compounds in organic synthesis: aminohydroxylation and diamination reactions. Chem. Soc. Rev. 33, 166-174 (2004).

2. Jensen, K. H. \& Sigman, M. S. Mechanistic approaches to palladium catalyzed alkene difunctionalization reactions. Org. Biomol. Chem. 6, 4083-4088 (2008).

3. McDonald, R. I., Liu, G. \& Stahl, S. S. Palladium(II)-catalyzed alkene functionalization via nucleopalladation: stereochemical pathways and enantioselective catalytic applications. Chem. Rev. 111, 2981-3019 (2011).

4. Schultz, D. M. \& Wolfe, J. P. Recent developments in palladium-catalyzed alkene aminoarylation reactions for the synthesis of nitrogen heterocycles. Synthesis 44, 351-361 (2012).

5. Cao, M.-Y., Ren, X. \& Lu, Z. Olefin difunctionalizations via visible light photocatalysis. Tetrahedron Lett. 56, 3732-3742 (2015).

6. Yin, G., Mu, X. \& Liu, G. Palladium(II)-catalyzed oxidative difunctionalization of alkenes: bond forming at a high-valent palladium center. Acc. Chem. Res. 49, 2413-2423 (2016).

7. Xiong, T. \& Zhang, Q. New amination strategies based on nitrogen-centered radical chemistry. Chem. Soc. Rev. 45, 3069-3087 (2016).

8. Wang, F., Chen, P. \& Liu, G. Copper-catalyzed radical relay for asymmetric radical transformations. Acc. Chem. Res. 51, 2036-2046 (2018)

9. Giri, R. \& KC, S. Strategies toward dicarbofunctionalization of unactivated olefins by combined Heck carbometalation and cross-coupling. J. Org. Chem. 83, 3013-3022 (2018).

10. Grigg, R. \& Sridharan, V. Palladium catalysed cascade cyclisation-anion capture, relay switches and molecular queues. J. Organomet. Chem. 576, 65-87 (1999)

11. Poli, G., Giambastiani, G. \& Heumann, A. Palladium in organic synthesis: fundamental transformations and domino processes. Tetrahedron $\mathbf{5 6}$ 5959-5989 (2000)

12. Vlaar, T., Ruijter, E. \& Orru, R. V. A. Recent advances in palladium-catalyzed cascade cyclizations. Adv. Synth. Catal. 353, 809-841 (2011).

13. Muzart, J. Three to seven C-C or C-heteroatom bonds from domino reactions involving a Heck process. Tetrahedron 69, 6735-6785 (2013).

14. Zhang, J.-S., Liu, L., Chen, T. \& Han, L.-B. Transition-metal-catalyzed threecomponent difunctionalizations of alkenes. Chem. Asian J. 13, 2277-2291 (2018).

15. Ping, Y., Li, Y., Zhu, J. \& Kong, W. Construction of quaternary stereocenters by palladium-catalyzed carbopalladation-initiated cascade reactions. Angew. Chem. Int. Ed. 58, 1562-1573 (2019)

16. Wu, X. \& Gong, L.-Z. Palladium(0)-catalyzed difunctionalization of 1,3dienes: from racemic to enantioselective. Synthesis 51, 122-134 (2019).

17. Petrone, D. A., Yen, A., Zeidan, N. \& Lautens, M. Dearomative indole bisfunctionalization via a diastereoselective palladium-catalyzed arylcyanation. Org. Lett. 17, 4838-4841 (2015).

18. Petrone, D. A., Kondo, M., Zeidan, N. \& Lautens, M. Pd(0)-catalyzed dearomative diarylation of indoles. Chem. Eur. J. 22, 5684-5691 (2016).
19. Zeidan, N., Beisel, T., Ross, R. \& Lautens, M. Palladium-catalyzed arylation/ heteroarylation of indoles: access to 2,3-functionalized indolines. Org. Lett. 20, 7332-7335 (2018)

20. Marchese, A. D., Lind, F., Mahon, Á., Yoon, H. \& Lautens, M. Forming benzylic iodides via a nickel catalyzed diastereoselective dearomative carboiodination reaction of indoles. Angew. Chem. Int. Ed. 58, 5095-5099 (2019).

21. Chen, S. et al. Palladium-catalyzed intramolecular dearomatization of indoles via decarboxylative alkynyl termination. Org. Lett. 18, 4016-4019 (2016)

22. Liu, J. et al. Palladium-catalyzed dearomatizing 2,5-alkoxyarylation of furan rings: diastereospecific access to spirooxindoles. Chem. Commun. $\mathbf{5 2}$ 9550-9553 (2016)

23. Xu, X., Liu, J., Lu, L., Wang, F. \& Yin, B. Pd-catalyzed regioselective intramolecular direct arylation of 3-indolecarboxamides: access to spiroindoline-3,3'-oxindoles and 5,11-dihydro-6H-indolo[3,2-c] quinolin-6-ones. Chem. Commun. 53, 7796-7799 (2017).

24. Qin, X., Lee, M. W. Y. \& Zhou, J. S. Nickel-catalyzed asymmetric reductive Heck cyclization of aryl halides to afford indolines. Angew. Chem. Int. Ed. 56, 12723-12726 (2017).

25. Wang, H. \& Wu, X.-F. Palladium-catalyzed carbonylative dearomatization of indoles. Org. Lett. 21, 5264-5268 (2019)

26. Liu, R.-R. et al. Palladium-catalyzed dearomative arylalkynylation of indoles Chem. Commun. 52, 13664-13667 (2016).

27. Liu, R.-R. et al. Enantioselective dearomative difunctionalization of indoles by palladium-catalyzed Heck/Sonogashira sequence. Angew. Chem. Int. Ed. 56, 7475-7478 (2017)

28. Shen, C. et al. Pd-catalyzed dearomative arylborylation of Indoles. Chem. Sci. 10, 3118-3122 (2019)

29. Weng, J.-Q., Xing, L.-L., Hou, W.-R., Liang, R.-X. \& Jia, Y.-X. Palladiumcatalyzed dearomative arylphosphorylation of indoles. Org. Chem. Front. 6, 1577-1580 (2019)

30. Liang, R.-X., Wang, K., Wu, Q., Sheng, W.-J. \& Jia, Y.-X. Palladium-catalyzed dearomative arylvinylation reaction of indoles with $\mathrm{N}$ Arylsulfonylhydrazones. Organometallics 38, 3927-3930 (2019).

31. Zeidan, N. \& Lautens, M. Migratory insertion strategies for dearomatization Synthesis 51, 4137-4146 (2019).

32. Pape, A. R., Kaliappan, K. P. \& Kündig, E. P. Transition-metal-mediated dearomatization reactions. Chem. Rev. 100, 2917-2940 (2000).

33. López Ortiz, F., Iglesias, M. J., Fernández, I., Andújar Sánchez, C. M. \& Ruiz Gómez, G. Nucleophilic dearomatizing (DNAr) reactions of aromatic C,Hsystems. A mature paradigm in organic synthesis. Chem. Rev. 107, 1580-1691 (2007).

34. Roche, S. P. \& Porco, J. A. Jr. Dearomatization strategies in the synthesis of complex natural products. Angew. Chem. Int. Ed. 50, 4068-4093 (2011).

35. Zhuo, C.-X., Zhang, W. \& You, S.-L. Catalytic asymmetric dearomatization reactions. Angew. Chem. Int. Ed. 51, 12662-12686 (2012).

36. Zhuo, C.-X., Zheng, C. \& You, S.-L. Transition-metal-catalyzed asymmetric allylic dearomatization reactions. Acc. Chem. Res. 47, 2558-2573 (2014).

37. Wu, W.-T., Zhang, L. \& You, S.-L. Catalytic asymmetric dearomatization (CADA) reactions of phenol and aniline derivatives. Chem. Soc. Rev. 45, 1570-1580 (2016)

38. Zheng, C. \& You, S.-L. Catalytic asymmetric dearomatization by transitionmetal catalysis: a method for transformations of aromatic compounds. Chem 1, 830-857 (2016)

39. Wertjes, W. C., Southgate, E. H. \& Sarlah, D. Recent advances in chemical dearomatization of nonactivated arenes. Chem. Soc. Rev. 47, 7996-8017 (2018)

40. Zuo, Z. et al. Palladium-catalyzed aryne insertion/arene dearomatization domino reaction: a highly chemoselective route to spirofluorenes. ACS Catal. 8, 11029-11034 (2018).

41. Liao, X., Wang, D., Huang, Y., Yang, Y. \& You, J. Highly chemo-, regio- and E/Z-selective intermolecular Heck-type dearomative $[2+2+1]$ spiroannulation of alkyl bromoarenes with internal alkynes. Org. Lett. 21, 1152-1155 (2019)

42. Pinto, A., Jia, Y., Neuville, L. \& Zhu, J. Palladium-catalyzed enantioselective domino Heck-cyanation sequence: development and application to the total synthesis of esermethole and physostigmine. Chem. Eur. J. 13, 961-967 (2007)

43. Kong, W., Wang, Q. \& Zhu, J. Palladium-catalyzed enantioselective domino Heck/intermolecular $\mathrm{C}-\mathrm{H}$ bond functionalization: development and application to the synthesis of (+)-Esermethole. J. Am. Chem. Soc. 137, 16028-16031 (2015).

44. Kong, W., Wang, Q. \& Zhu, J. Synthesis of diversely functionalized oxindoles enabled by migratory insertion of isocyanide to a transient $\sigma$-alkylpalladium (II) Complex. Angew. Chem. Int. Ed. 55, 9714-9718 (2016)

45. Kong, W., Wang, Q. \& Zhu, J. Water as a hydride source in palladiumcatalyzed enantioselective reductive Heck reactions. Angew. Chem. Int. Ed. 56, 3987-3991 (2017)

46. Tong, S., Limouni, A., Wang, Q., Wang, M.-X. \& Zhu, J. Catalytic enantioselective double carbopalladation/C-H functionalization with statistical 
amplification of product enantiopurity: a convertible linker approach. Angew. Chem. Int. Ed. 56, 14192-14196 (2017).

47. Carmona, R. C., Köster, O. D. \& Correia, C. R. D. Chiral, N. N ligands enabling palladium-catalyzed enantioselective intramolecular Heck-Matsuda carbonylation reactions by sequential migratory and $\mathrm{CO}$ insertions. Angew. Chem. Int. Ed. 57, 12067-12070 (2018).

48. Zhang, Z.-M. et al. Enantioselective dicarbofunctionalization of unactivated alkenes by palladium-catalyzed tandem Heck/Suzuki coupling reaction. Angew. Chem. Int. Ed. 58, 14653-14659 (2019).

49. Bai, X., Wu, C., Ge, S. \& Lu, Y. Pd/Cu-catalyzed enantioselective sequential Heck/Sonogashira coupling: asymmetric synthesis of oxindoles containing trifluoromethylated quaternary stereogenic centers. Angew. Chem. Int. Ed. 59, 2764-2768 (2020).

50. Zhou, L. et al. Enantioselective difunctionalization of alkenes by a palladiumcatalyzed Heck/Sonogashira sequence. Angew. Chem. Int. Ed. 59, 2769-2775 (2020).

51. Shen, C. et al. Enantioselective arylative dearomatization of indoles via Pdcatalyzed intramolecular reductive Heck reactions. J. Am. Chem. Soc. 137, 4936-4939 (2015).

52. Liu, R.-R. et al. Spirooxindole synthesis via palladium-catalyzed dearomative reductive-Heck reaction. Org. Biomol. Chem. 15, 2711-2715 (2017).

53. Liang, R.-X., Yang, R.-Z., Liu, R.-R. \& Jia, Y.-X. Palladium-catalyzed asymmetric dearomative alkenylation of indoles through reductive-Heck Reaction. Org. Chem. Front. 5, 1840-1843 (2018).

54. Li, X. et al. Palladium-catalyzed enantioselective intramolecular dearomative Heck reaction. J. Am. Chem. Soc. 140, 13945-13951 (2018).

55. Xie, J. \& Zhou, Q. Magical chiral spiro ligands. Acta Chim. Sin. 72, 778-797 (2014).

56. Chowdhury, S. et al. Discovery of XEN907, a spirooxindole blocker of NaV1.7 for the treatment of pain. Bioorg. Med. Chem. Lett. 21, 3676-3681 (2011).

\section{Acknowledgements}

We are grateful for the financial support from the National Natural Science Foundation of China (21772175 and 91956117, Y.-X.J.; 21702184, R.-X.L.; 21702182 and 21873081, X.H.), China Postdoctoral Science Foundation (2019M652056, H.W.), Fundamental Research Funds for the Central Universities (2019QNA3009, X.H.), the State Key Laboratory of Clean Energy Utilization (ZJUCEU2020007, X.H.). Calculations were performed on the highperformance computing system at the Department of Chemistry, Zhejiang University.

\section{Author contributions}

Y.-X.J. and X.H. conceived the idea and supervised the whole project. B.Z., Z.-Y.C., J.-W.Z., R.-X.L. designed and carried out the experiments. H.W. carried out the DFT calculation. All authors discussed the results, contributed to writing and commented on the paper, and approved the final version of the paper for submission.

\section{Competing interests}

The authors declare no competing interests.

\section{Additional information}

Supplementary information is available for this paper at https://doi.org/10.1038/s41467020-18137-w.

Correspondence and requests for materials should be addressed to X.H. or Y.-X.J.

Peer review information Nature Communications thanks the anonymous reviewer(s) for their contribution to the peer review of this work. Peer reviewer reports are available.

Reprints and permission information is available at http://www.nature.com/reprints

Publisher's note Springer Nature remains neutral with regard to jurisdictional claims in published maps and institutional affiliations.

\section{(c) (i)}

Open Access This article is licensed under a Creative Commons Attribution 4.0 International License, which permits use, sharing, adaptation, distribution and reproduction in any medium or format, as long as you give appropriate credit to the original author(s) and the source, provide a link to the Creative Commons license, and indicate if changes were made. The images or other third party material in this article are included in the article's Creative Commons license, unless indicated otherwise in a credit line to the material. If material is not included in the article's Creative Commons license and your intended use is not permitted by statutory regulation or exceeds the permitted use, you will need to obtain permission directly from the copyright holder. To view a copy of this license, visit http://creativecommons.org/ licenses/by/4.0/

(c) The Author(s) 2020 